\title{
Project Management in the Social Sphere: Essence and Problems of Implementation
}

\author{
Natalia Shturbina ${ }^{1, a *}$, Igor Bashkatov ${ }^{1, b}$ \\ 1 Russian Presidential Academy of National Economy and Public Administration, Prospect \\ Vernadskogo, 119571, 84, bldg 2 Moscow, Russia \\ arazvitiev@bk.ru, bigb_kog@mail.ru \\ ${ }^{*}$ Corresponding author
}

Keywords: corporate social responsibility, sustainability of development, organizational management systems, traditional management system, project management, project management in the social sphere, balance of interests, educational systems

\begin{abstract}
Based on the analysis of current trends in the socio-economic development of educational systems and the practice of implementing project management in them, this paper develops recommendations for training personnel for implementing project management in education. Difficult conditions for the development of modern educational systems predetermined the relevance of the transition to fundamentally new systems of organizational management. The key difference between such systems and traditional management systems is that they take into account cultural and value features of organizations, which requires the integration of formal and informal management mechanisms. In this regard, project management is considered as a way to systematically use the tools of the formal mechanisms for managing an organization and integrating them with informal mechanisms. At present, the conditions have been created for introducing project management into the practice of organizations. At the same time, the specificity of educational systems requires special and finetuning of project management mechanisms. This article is devoted to identifying the features of such a setting and making recommendations on training for the implementation of project management in education.
\end{abstract}

\section{Introduction}

In the conditions of high dynamics of external environment factors, the whole world community is forced to develop new forms of social relations in order to support the sustainability of its development. This is due to the fact that focusing only on an economic component of such activity loses its absolute importance in the context of the current situation. The significance of the moral component of any activity, attention to social problems, both inside and outside the social sphere, increases. Currently, it is becoming a success factor in the development of the education system.

In modern management, such a position is expressed by the concept of corporate social responsibility (CSR). The basic principle of management in the format of this concept is the principle of ensuring a balance of interests of all parties interested in the sustainable social and economic development of all spheres of activity.

In our study, we analyze possible approaches to the implementation of the CSR concept in education. The key requirements for its development are presented in the works [1], [2], [3], [10].

\section{Methodology}

\subsection{Trends in changing social responsibility}

In its continuous development, any social system strives for perfection. The world community has developed a model of a perfect organization "European Foundation for Quality Management" (EFQM). The model is based on corporate social responsibility, which a particular organization assumes in its development. As the idea of social responsibility changes, the content of this definition changes. So, if the 2003 EFQM model operated directly with the concept of corporate social responsibility, then the 2013 EFQM model already considers CSR in the context of building responsibility for a sustainable future. In the 2013 EFQM model, the CSR content is more focused on creating a sustainable future. With the changing 
content of the model of perfection, its basic principle remains unchanged, which emphasizes the integrity of the model itself [7].

The development of CSR as a phenomenon has led to the emergence of the GOST R ISO 26000-2012 standard in Russia: "The national standard of the Russian Federation. Guidelines on social responsibility (approved and put into effect by the Order of Rosstandart of November 29, 2012, No. 1611-Art.).

One of the key provisions of this document [17] determined the objective need for changing the management system in organizations so that it could take full responsibility.

In this work, it is clearly defined that the existing management system, which is based only on rigid structures and processes and using formal management mechanisms, does not allow an organization to ensure social responsibility on the proper level. In this regard, the concept of "organizational management" is introduced, and the whole paragraph of the standard is devoted to the disclosure of it in the context of social responsibility.

In a generalized form, the differences between a traditional management model and a perspective model of organizational management are presented in Table 1.

TABLE 1. FUNDAMENTAL DIFFERENCES IN MANAGEMENT MODELS.

\begin{tabular}{|c|c|c|}
\hline Features & $\begin{array}{l}\text { Traditional } \\
\text { management model }\end{array}$ & $\begin{array}{c}\text { Perspective model } \\
\text { organizational management }\end{array}$ \\
\hline Control type & Process management & Project management \\
\hline Managment structure & Rigid hierarchical & Matrix (task, project) integrated into a rigid structure \\
\hline Control mechanisms & Rigid process management & Accounting for cultural and value features of organizations \\
\hline Management model & "Order - response" & $\begin{array}{l}\text { Managing contradictions through the formation of a special } \\
\text { set of conditions (environment) }\end{array}$ \\
\hline $\begin{array}{l}\text { Features of effective } \\
\text { management }\end{array}$ & $\begin{array}{l}\text { Accurate execution of } \\
\text { orders }\end{array}$ & $\begin{array}{l}\text { Initiative, professional activity, personal interest and } \\
\text { personal responsibility of employees }\end{array}$ \\
\hline $\begin{array}{l}\text { Management quality } \\
\text { indicators }\end{array}$ & Quantitative indicators & $\begin{array}{l}\text { Quantitative indicators in the context of qualitative } \\
\text { assessments }\end{array}$ \\
\hline $\begin{array}{l}\text { Quality management } \\
\text { criteria }\end{array}$ & $\begin{array}{l}\text { Maximum (minimum) of } \\
\text { quantitative indicators }\end{array}$ & $\begin{array}{l}\text { Reduction of social tension, improvement of the quality of } \\
\text { life, improvement of the natural environment, achievement } \\
\text { of personal involvement of everyone in overcoming social } \\
\text { problems. }\end{array}$ \\
\hline
\end{tabular}

A detailed analysis of the differences in control models is presented in [6], [8], [9], [11], [12], [13], [14], and [15].

Here we will focus on the consideration of fundamental differences in the content of the following concepts: "management" and "organizational management."

Traditional "management" is built on rigid structures and processes. For ensuring the functioning of management in such structures, formal mechanisms are used. Evaluation of management quality is carried out mainly through quantitative indicators. The key task of the head of an organization in this case is to coordinate the activities of all structural units towards the achievement of strategic development goals, guided by quantitative indicators measuring the quality of activities.

"Organizational management" focuses on the sharing of both (a) formal management mechanisms based on rigid structures and (b) processes and informal mechanisms arising from the culture and values of the organization. The implementation of informal mechanisms remains problematic today. The reason for this state of affairs is due to the complexity of the qualitative assessment of the characteristics determined by cultural and value diversity of organizations. In addition, in the organizational management, the human factor is very strong, and the quality of such management is directly determined by individuals or groups of people who have power and are responsible for achieving organization's goals.

The differences noted are fundamental, since the organizational structure is changing. The soft matrix structure (project, task, etc.) is integrated into the rigid structure of distribution of powers. As it is known, a 
change in structures is followed by a change in functions [7].

In the new structure, the key function will become not just the coordination of the activities of structural units, as it is done in traditional management, but the organization of the systemic use of the tools of formal management mechanisms of an organization to involve all employees towards achieving the goals of its strategic development.

To effectively implement this function in modern conditions, management technologies based on the project approach are being actively tested and implemented. In this regard, project management is appropriate to consider as a way to systematically use the tools of formal mechanisms for managing an organization and integrating them with informal mechanisms.

\subsection{Trends in changing the concept of sustainable development in the social sphere}

In the most general case, the CSR development is aimed at ensuring sustainable socio-economic development of the state. In this sense, CSR and sustainability are two sides of the same coin.

There are many varieties of sustainability and being formed. For example, according to the features of "nature of external factors," or "signs of the environment," and "levels of development of compensatory mechanisms," the following groups of sustainability are distinguished [5]:

Visible stability. It manifests itself in the event that some of the signs of the environment are unchanged and the system does not have appropriate compensation mechanisms.

Delayed stability. This group implies that the system has the opportunity to completely withdraw from the action of the perturbing factor and not even have the appropriate compensatory mechanisms.

Adaptive stability of the 1st kind. It assumes the presence in the system of a limited (obviously incomplete) set of mechanisms, which, however, are able to compensate for external disturbance by creating "absorbing" adaptive chains from combinations of existing elements. The carriers of compensation mechanisms are employees of the organization, so in this case it is appropriate to talk about the direct reaction of employees of an organization to the effect of disturbances.

Adaptive stability of the 2nd kind. It has a similar compensation mechanism. However, in this case, the chain is not linear, but closed into a cycle, as a result of which it is possible to compensate for the disturbance in several "passes", which is more powerful than a separate chain. In essence, this is a feedback mechanism. With regard to social systems, such sustainability is ensured by the involvement of the organization's employees in the systematic project activities to achieve strategic goals of the organization's development.

Group stability. This is a case of true sustainability, when the system has a complete group of compensatory mechanisms for all possible types of changes in principle (including the "damage" of the mechanisms themselves). The implementation of this mechanism is, undoubtedly, extremely wasteful, especially since surprises also occur here.

This typology of sustainability can be represented by the scheme presented in Figure 1. In this case, group sustainability combines all the quadrants.

The use of such a typology makes it possible to identify and visualize the features of project management of the social sphere in the context of CSR. In traditional project management (all spheres with the exception of social), visible stability with elements of delayed and adaptive stability of the first kind dominates. This state of affairs is noted in Figure 2.

At the same time, the visible stability is provided by quantitative indicators characteristic of the traditional management model (see Table 1). Stability itself is characterized by positive dynamics of these indicators. In other words, if the positive dynamics of indicators is ensured by the project implementation years, the project is considered successful. 


\section{The level of development of compensation mechanisms}

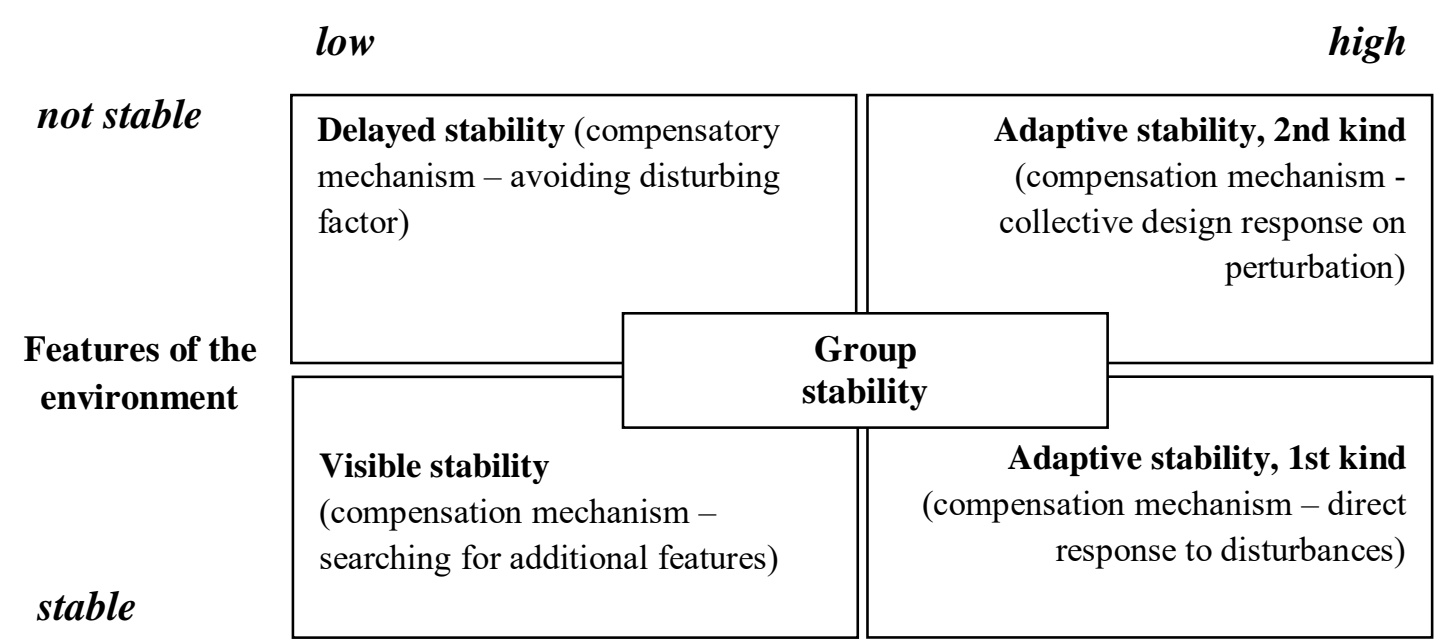

Fig.1. Typology of stability.

The level of development of compensation mechanisms

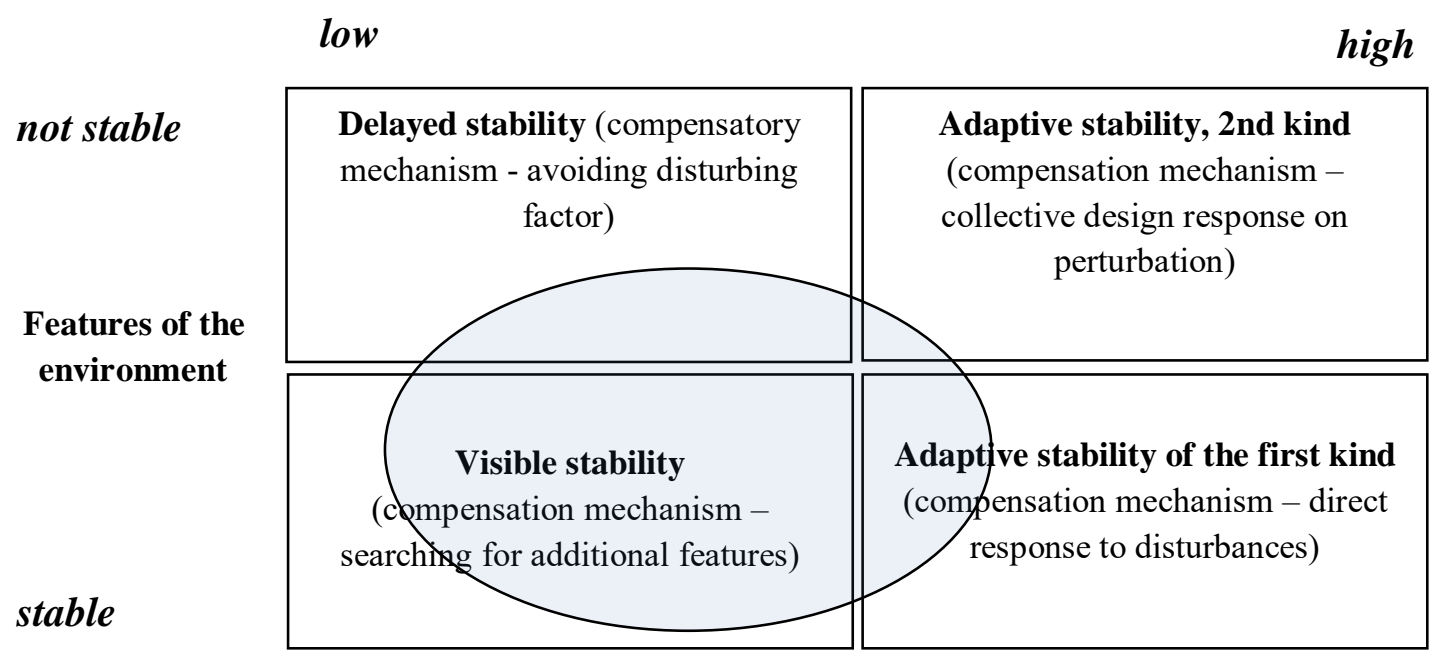

Fig. 2. The dominant stability of traditional project management.

Delayed stability is expressed by such a subject area of project management as "project assumptions and limitations", where essentially there is a departure from disturbing factors. Adaptive sustainability of the first kind is expressed by such a subject area as the "risks and opportunities" of the project, for example [4], [20].

Project management in the social sphere is already more focused on ensuring adaptive sustainability of the 1 st and 2 nd order, since the dynamics of changes in the factors of the external environment have significantly increased and their disturbing effects are intensified. Sustainable development in such conditions can only be achieved when the balance of interests of all parties interested in sustainable socio-economic development is ensured, cultural and value features of organizations are taken into account, social tensions are reduced, the quality of life is improved, the environment is improved, and the individuality is achieved in overcoming social problems, etc. [20] 
In other words, we are talking about the features of the social sphere. These features are determined by the following factors:

- inconsistency of the social object;

- multi-vector development of a social object;

- the impossibility of describing a social object by a finite number of terms of any social theory (fundamental non-formalizability);

- the multi-factorial existence of a social object;

- subjective factors in the formation of social expectation, social forecast, and social design.

The dominant stability of project management in the social sphere is presented in Figure 3.

\section{The level of development of compensation mechanisms}

low

\section{high}

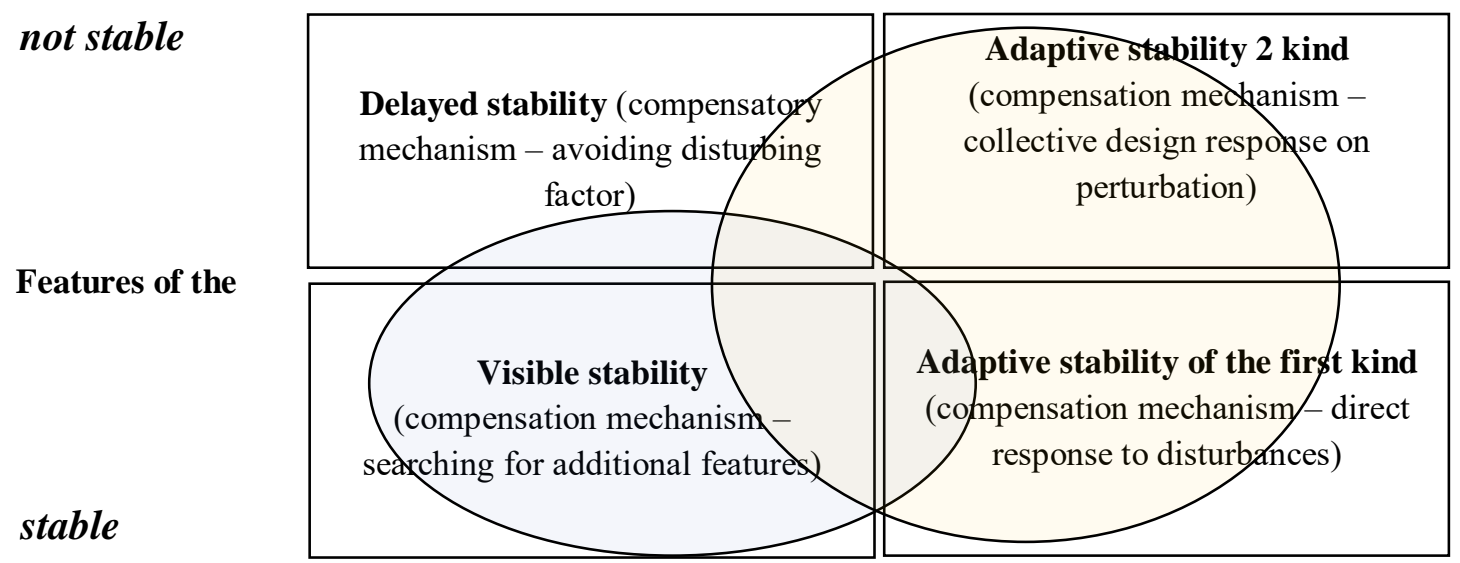

Fig. 3. The dominant sustainability of project management in the social sphere.

The complexity of the implementation of adaptive sustainability in the social sphere due to the following provisions:

- the need for an adequate reproduction of design decisions in various situations;

- the difficulty of expressing social processes in quantitative terms;

- great dependence on the value position of participants and project developers;

- the need to maximize understanding and consideration of cultural specifics, which eventually becomes an object of project activities;

- the complexity of exporting their own cultural patterns (values, norms, and technologies) into the "alien" cultural context, which is thereby modified and "artificially" transformed.

The above difficulties predetermined a special understanding of stability in the social sphere: the stability of an organization is determined by positive dynamics of development targets determined by initiative, project activity, personal interest, and personal responsibility of each employee for achieving strategic indicators of educational systems development.

Such an understood stability gives a special perception of perfect organizations that include ethical thinking, values and the highest standards of organizational behavior in their culture, which allows them to strive for economic, social, and environmental stability. 


\section{Study}

Recommendations for training the implementation of project management in education.

As noted in article [19], the development of any systems directly depends on the efficiency of their management. In the education system for many years, the managerial emphasis was not on the application of management laws, but on pedagogical approaches to the development of systems. Perhaps this was one of the factors reducing the effectiveness of education.

The need to change the paradigm of managing the development of educational systems has been long overdue. Since 2011, we have been witnessing the implementation of projects for the development of educational systems, especially graduates of Presidential and other programs of RANEPA. After the Resolution of the Government of the Russian Federation of October 15, 2016 No 1050 "On the organization of project activities in the Government of the Russian Federation" (together with the "Regulations on the organization of project activities in the Government of the Russian Federation"), many educational systems at the regional and municipal level began to introduce project management models, such as "Project offices" and "Project cabinets."

Analyzing the experience of introducing project management in the education system, it can be noted that this tool allows you to increase the effectiveness of systems through improving the development management system. In 2017, in response to the state policy objectives of introducing a project approach to management in government, the activity of formally introducing models of project management increased many times, but, contrary to expectations, brought a lot of negative consequences. We will review the main "project management diseases".

\section{Is this a project?}

The national standards state that "the goal of the project is to obtain measurable advantages and subsequently to realize the chosen opportunities" $[4,18]$.

Analyzing more than 3000 projects proposed by the heads of educational organizations, it was revealed that managers often do not see a measurable goal, cannot offer a unique product or service. Most often there is a description of well-known strategic slogan directions, which further turn into an unreasonable set of measures. Many projects are the intention of conducting any research or development of any methodical product.

The teams working on the project could not open the problem area and, accordingly, propose an idea to solve the contradiction or problem. There is a tendency to almost replace the topicality and the problem area of the project with the name of the state document, which in itself does not give any idea which process is planned to be improved or the efficiency of which process should be increased.

Many of the considered municipal projects were a description of the results that need to be improved, omitting the autopsy of the reasons for these results, that is, almost a description of their own functions.

When trying to describe necessary resources, the phrase "funds for the project are available" was often encountered, although further analysis showed that many of the staff's labor costs were not taken into account. The authors of some projects planned costs that did not correspond to the goals and objectives of the projects.

The analytical review of the project section "expected results" showed that often all the indicators $t$ in the system are placed here, and many of them are weakly linked to the project idea.

Thus, it is possible to identify the main disease of project management: more than $80 \%$ of the considered project proposals cannot be called the projects aimed at developing educational systems. Consequently, the economic efficiency (as a ratio of labor and productivity) is very low. In one spent a lot of time on development, there would be many activities that not bring tangible improvements in the quality indicators of the education system.

\section{All waste of projects ...}

As soon as government policy began to give a focus on a project-based approach to management, managers immediately began to respond with an abundance of projects. Any part of the process began to br 
"called" a project. An analysis of project proposals made by 100 heads of municipal education systems and 300 leaders of educational organizations shows that practically everything that lies in the functional responsibilities of managers and teachers is the basis for the so-called "projects". Thus, a negative tendency to misunderstand what a real system development project is further aggravated. Employees are now more often replace a project with usual process steps. Imitation of a plurality of projects is created, but in reality no more than $10 \%$ of the described project proposals are such.

\section{Project management is like?}

The next stage in the development of project management can be described as follows: a project has been developed, and they have not learned how to manage its implementation. Having conducted more than 30 focus groups on the topic of project management, one can identify a common "illness". Managers do not have an understanding of a project management system in their organization. As soon as there are more than 5 projects, control and quality decrease. We actually have no stage of "project completion". Virtually no final product in educational systems has been completed. Here comes a stage where there is no clear system of control: whether projects are being implemented productively, what common deviations are, what results of progress towards strategic goals, etc.

\section{Project portfolios and development strategy: is it about different ...?}

We must pay tribute to the fact that it was the state policy in terms of the implementation of project management that gave an understanding to many managers of the need to implement "project portfolios" that would allow them to manage projects at least through combining them into portfolios.

According to the standard [18], "Project portfolio management should consist of a set of interrelated organizational processes and methods by which the organization allocates and distributes the resources necessary to achieve strategic goals". However, in practice it turned out to be different. An analysis of the proposed portfolios of 30 educational organizations in different regions revealed two problems:

1) The name and content of portfolios did not correlate with the strategic directions of development (project portfolios lived in their own separate areas, not helping the implementation of the system development strategy).

2) The description of portfolios was too broad, formal, and did not give the staff a sense of what projects need to be developed in order to achieve the intended strategic results.

Thus, such an important project management tool as a portfolio of projects is poorly understood by practitioners.

\section{The Project Office: THIS IS WHAT? WHERE IS IT? WHY IS IT?}

In project management, an important component is the structural construction of its model and the correct content filling. A survey of more than 100 managers showed that the majority do not understand what the Project Office, the Project Committee are, and they even confuse their functionality. Without understanding the essence, they distribute employees in different structures of project management incorrectly.

\section{I will not give power ...}

In conclusion, we will focus on one more painful point of project management. The leaders on all the "steering" positions are trying to put pressure on administrative workers. This negatively affects the efficiency of project management as:

- Administrative workers are already loaded with the functionality to ensure the processes of the system;

- Pedagogical workers understand that they again become executors of other people's decisions, which, of course, reduces motivation and responsibility. Although in this paradigm of project management there is an opportunity for horizontal career of employees when they can take the position of project manager, portfolio, office or committee. And this approach, in some cases, reduces the likelihood of professional burnout. 
An analysis of the practice of supporting the implementation of project management in educational systems by our Center for the Development of Educational Systems shows that the "treatment" of the above project management diseases lies primarily in the field of training of staff for project management in education. We have identified the following necessary steps.

1. Develop the structure and content of a project model of management of a regional education system during the joint training of all managers and teams of structural units of the regional Ministry of Education, municipal educational systems, and heads of educational organizations. Thus, it is possible to achieve the implementation of project management on a single methodological basis for managers of different levels, allowing to develop a common project language, a common understanding and a common management style, which would significantly reduce the time for coordinating management decisions on the development of the system as a whole.

2. Create regional project management laboratories. Laboratories staffed with specialists who have undergone the necessary training, during which the entire process of training and development of systems was covered.

3. Prepare teams of specialists from educational development institutes responsible for teaching the project approach of management personnel of a regional education system.

4. In the municipalities selected as supporting ones, prepare specialists as well as heads of educational organizations for pilot implementation of a project management model.

5. Prepare teams of supporting educational organizations, Project offices and Project committees, for the implementation of a project management model of educational organizations and systems.

For the effective implementation of the above areas, it is necessary to take into account the recommendations approved by our Center for the Development of Educational Systems (RANEPA):

- Move from individual leadership training to training management teams of an organization, municipal and regional systems, which should include representatives of a personnel reserve. Thus, the formation of a personnel reserve will be embedded in the practical reality of the development of an educational system itself.

- Introduce project forms of work in small groups as the main tool for developing managerial competencies. The final products should be a project management model and portfolios with educational system development projects.

- The learning process must be diluted in time: at stage 1, the content of portfolios is created; at stage 2 , projects are developed as part of portfolios.

- The learning process is done with a consulting bias. To do this, enter the 3rd stage of training, during which there are both maintenance and expert evaluation of the results of project implementation.

- In the process of learning, it is necessary to introduce successful leaders and practitioners for teaching and for the expert evaluation of projects, as well as focusing on results of their implementation.

- Include a training internship design and analytical sessions in those organizations where management teams introduce all employees to the organization management process through the development of the Development Strategy and its implementation projects.

- For expert evaluation of final projects, invite officials of different levels, representatives of the public, science, parents, employers, etc.

- During training, conduct an expert assessment focused on the level of development of managers' project competencies who can be given recommendations for their appointment (personnel reserve) for a certain level of project management.

- Create an information portal for managing the project preparation and implementation system, disseminating experience (information on each program in the region, evaluating its performance 
by students, independent evaluation of developed projects, and expert evaluation of the project implementation).

- Implement a system of competitive mechanisms for the selection of project management models, projects of different levels (both developed and implemented).

\section{Conclusion}

- Created a reliable tool for introducing advanced organizational management systems into the practice of educational systems, based on the project approach;

- Applied to the social sphere, this tool requires a fine and highly professional adjustment based on ethics of non-violent and conflict-free solution of project participants' social and personal problems;

- Sustainability of perfect organizations' socio-economic development in the 21 st century can only be ensured by changing all project participants' thinking, who must be proactive, have a personal interest, and be responsible for a sustainable future.

\section{References}

[1] Government of Russia. (2012). Federal Law of December 29, 2012 No. 273-FL "On Education in the Russian Federation."

[2] Government of Russia. (2018). Decree of the President of the Russian Federation of May 7, 2018 No. 204 "On national goals and strategic objectives in the development of the Russian Federation for the period up to 2024."

[3] Government of Russia. (2017). The state program of the Russian Federation "Development of education for 2018-2025," approved by the Decree of the Government of the Russian Federation of December 26, 2017 No. 1642.

[4] Government of Russia. (2016). Resolution of the Government of the Russian Federation of 10.15.2016 N 1050 "On the organization of project activities in the Government of the Russian Federation."

[5] Sergeev, A. V. (2008). Socio-economic sustainability of the development of regions. Vestnik TISBI, 4, pp. 13-18

[6] Bashkatov, I. P. (2018). Inside View: Lessons from the implementation of project management in the practice of educational systems. In M. G. Pugacheva (Ed.), Project management as a tool for the development of educational systems: from project to project portfolio management: proceedings of the Third Annual International Scientific practical conference of prolonged action "Management of the development of educational systems" (October 20-21, 2017, Moscow) (pp.7-12). Moscow, Russia: Delo Publishing House.

[7] Bashkatov, I. P., \& Teslinov, A. G. (2015). The development of organizations as management systems. Book 1: Technology systems understanding of organizations. Zhukovsky, Russia: MIM LINK.

[8] Bashkatov, I. P. (2012). Rating as a tool for strategic planning. Scientific Review. Series 1. Economics and Law, 1, pp.146-155.

[9] Bashkatov, I. P., \& Sergeeva, T. A. (2012). Mechanisms for introducing innovations into the practice of companies' activities. Financial Economics, 2, pp.71-79.

[10] Bashkatov, I. P. (2010). Audit of the effectiveness of budget spending as a tool for the innovative development of colleges. M. V. Nikitin (Ed.), Innovative development of primary and secondary vocational education: experience, problems and prospects: proceedings of the interregional conference (October 24-26, 2010) (pp. 24-29). Moscow, Russia: APO Center IRPO.

[11] Bashkatov, I. P. (2012). Mechanisms for introducing innovations into the practice of companies' activities. Financial Economics, 2, pp. 71-79.

[12] Bashkatov, I. P. (2015). Prospective systems of organizational management of educational organizations: the nature and problems of implementation (p. 16). Moscow, Russia: 1 MOQ. 
[13] Bashkatov, I. P. (2015). Efficiency of the education system: a study for understanding (p. 8). Moscow, Russia: 1 MOK.

[14] Bashkatov, I. P., Maksimchenko, T. V., Kharkova, E. V., \& Sergeeva, T. A. (2015). Development of the methodological basis for the formation of effective organizational management systems of multifunctional educational complexes. Moscow, Russia: MIOO.

[15] Bashkatov, I. P. (2015). Formation of effective systems of organizational management of a multifunctional educational complex: methodological recommendations. Moscow, Russia: MIOO.

[16] Bashkatov I. P. (2010). The concept of organizing a system of activity when performing a complex of scientific research work. Serpukhov, Russia.

[17] Government of Russia. (2012). GOST R ISO 26000-2012: National standard of the Russian Federation: a guide to social responsibility (approved and enacted by Order of Rosstandart dated 11.29.2012 N 1611-Art).

[18] Government of Russia. (2015). GOST R ISO 21500-2014 Guidelines for project management. Moscow: Rosstandart.

[19] Shturbina, N. A. (2018). Pains of the formation of project management in education and mechanisms of their treatment: recommendations for training. In M. G. Pugacheva (Ed.), Project management as a tool for the development of educational systems: from a project to project portfolio management: proceedings of the Third Annual International Scientific and Practical Conference of Prolonged Action "Managing the Development of Educational Systems" (October 20-21, 2017, Moscow) (pp.17-22). Moscow, Russia: Delo Publishing House.

[20] WinBD. (2019). Project management in the field of higher education and science. Retrieved from http://winbd.ru/news/2019. 